Illinois State University

ISU ReD: Research and eData

Theses and Dissertations

$4-2-2014$

\title{
Evaluating Factors that Influence Treatment Integrity During Peer Consultation
}

Jennifer Ann Arms

Illinois State University, jnt00@hotmail.com

Follow this and additional works at: https://ir.library.illinoisstate.edu/etd

Part of the Special Education Administration Commons, and the Special Education and Teaching Commons

\section{Recommended Citation}

Arms, Jennifer Ann, "Evaluating Factors that Influence Treatment Integrity During Peer Consultation" (2014). Theses and Dissertations. 97.

https://ir.library.illinoisstate.edu/etd/97

This Thesis is brought to you for free and open access by ISU ReD: Research and eData. It has been accepted for inclusion in Theses and Dissertations by an authorized administrator of ISU ReD: Research and eData. For more information, please contact ISUReD@ilstu.edu. 


\title{
EVALUATING FACTORS THAT INFLUENCE TREATMENT INTEGRITY DURING PEER CONSULTATION
}

\author{
Jennifer A. Arms
}

63 Pages

May 2014

Many schools are using consultation in order to provide students with disabilities adequate services mandated by IDEA (2004). However, consultation is only effective if consultee's implement treatment plans with high levels of treatment integrity (Noell et al., 2005; Sanetti \& Kratochwill, 2008). There are many factors that influence consultee's treatment integrity. The current study examines teacher respondents' answers to the Evaluating Factors that Influence Treatment Integrity During Consultation Survey. Results indicate the teacher consultees believe peer educational consultants to have more knowledge in the area of behavior. Further results indicate that there are up to 19 factors that teachers rate as important in the consultation process. 


\title{
EVALUATING FACTORS THAT INFLUENCE TREATMENT INTEGRITY DURING PEER CONSULTATION
}

\author{
JENNIFER A. ARMS
}

A Thesis Submitted in Partial Fulfillment of the Requirements for the Degree of

\section{MASTER OF SCIENCE IN EDUCATION}

Department of Special Education

ILLINOIS STATE UNIVERSITY 


\section{EVALUATING FACTORS THAT INFLUENCE TREATMENT INTEGRITY DURING PEER CONSULTATION}

JENNIFER A. ARMS

COMMITTEE MEMBERS:

Christina M. Borders, Chair

Stacey J. Bock

Mark S. Zablocki 


\section{ACKNOWLEDGMENTS}

First I would like to thank the amazing instructors and staff at Illinois State University. Without your guidance and knowledge I would not be the teacher and consultant I am today. More specifically I would like to thank my thesis chair, Dr. Christy Borders for her steadfast support over the last few months in the completion of this thesis project. Without your guidance, I would still be staring at a bunch of data without real thought on how to get any answers out of it, so thank you.

Secondly to my thesis committee co-chairs, Dr. Stacey Jones-Bock and Dr. Mark Zablocki, thank you for your added guidance and help in making sure this was the best product that I could produce. To Dr. Zablocki, thank you for your guidance in helping take a lot of information and arranging it so that it gave me the best start to this process. To Dr. Bock, thank you for your keen eye during the editing process and your timely responses to my questions.

Next I'd like to say thank you to my parents. You have always been there for me throughout my life and helping me accomplish this goal has been no different. You were always there to lend a helping hand and an ear to vent when needed. Thank you for saving my sanity more than once throughout this process. You helped me begin my secondary education and it is only fitting that you helped me further it.

Finally, to my husband Tony, you do not probably understand what you have done for me throughout this process. Whether it was listening to me ramble, helping me 
solve a computer problem, or just simply being there, I owe most of this to you. You have always supported me, always encouraged me to push myself to be more, and have told me more times than I can count that I can do anything if I want to. You've never questioned me even when I questioned myself, so thank you. Thank you for everything that you have always been.

J.A.A. 


\section{CONTENTS}

Page

ACKNOWLEDGEMENTS $\quad$ i

CONTENTS $\quad$ iii

TABLES vi

CHAPTER

I. THE PROBLEM AND ITS BACKGROUND 1

Statement of the Problem 1

Current Demands of Classrooms 2

Consultation 2

Models of Consultation 3

Instructional consultation model $\quad 3$

Behavioral consultation model 4

Behavioral Consultation Process $\quad 5$

Problem identification $\quad 5$

Problem analysis $\quad 6$

Plan implementation $\quad 6$

Treatment evaluation $\quad 8$

Behavioral Consultation and Treatment Integrity 8

$\begin{array}{lr}\text { Conclusion } & 9\end{array}$

II. REVIEW OF RELATED LITERATURE 10

Factors that Influence Treatment Integrity 11

Leadership Style $\quad 11$

$\begin{array}{ll}\text { Skill Level } & 13\end{array}$

Social Power Strategies $\quad 14$ 
Consultee Acceptance of Treatment Plans 16

Time

Training

Consultant Follow-up Strategies

Meetings

Performance feedback

Teacher self-report

Structured interviews

Student Outcomes

Conclusion and Research Gap

Research Purpose and Questions

Questions

III. METHODOLOGY

Research Questions

Research Design

Setting

Participants

28

Survey Instrument

Procedure

Data Analyses

IV. RESULTS

Findings

Research Questions

Additional Results

V. SUMMARY, DISCUSSION, IMPLICATIONS, AND RECOMMENDATIONS

Overview of the Study

Statement of the Problem

Purpose of the Study

Research questions 
Method

Participants 46

Survey Instrument $\quad 46$

Data Analyses $\quad 47$

Summary and Discussion of Major Findings 47

Research Question 1

Research Question $2 \quad 48$

Additional Results 48

Implications for Practice $\quad 49$

Limitations of the Study 49

Recommendations for Future Research 50

Conclusion $\quad 52$

$\begin{array}{ll}\text { REFERENCES } & 53\end{array}$

APPENDIX A: $\quad$ Evaluating Factors that Influence Treatment Integrity During 57

Consultation Survey

APPENDIX B: $\quad$ Recruitment Email 62 


\section{TABLES}

Table $\quad$ Page

1. Social Power Bases 15

2. Demographic Information 30

3. Combined Survey Question Percentages 35

4. Combined Factor Means $\quad 37$

5. Previous Contact Factor Means 39

6. No Previous Contact Factor Means 41

7. Factor Significance Levels 43 


\section{CHAPTER I}

\section{THE PROBLEM AND ITS BACKGROUND}

\section{Statement of the Problem}

Today's schools are tasked with meeting the needs of very diverse learners, and many schools are using consultation services in order to meet all students' needs. Consultation within the school environment can look different depending on the intended outcome of the consultative relationship. Experts in the field of both learning and behavior are often asked to assist teachers with both individual and groups of students who are struggling within the educational environment. Through the process of consultation, schools often hope to improve students' rates of success in both areas of learning and behavior. Consultation can be effective in meeting students' academic (Rosenfield, 1987) and behavioral (Bergan \& Kratochwill, 1990) needs. However, consultation is only effective when teachers (i.e., consultees) implement treatment plans developed through consultation with integrity (Noell et al., 2005; Sanetti \& Kratochwill, 2008). Treatment integrity has been defined by Lane, Bocian, MacMillan, and Gresham (2004) as "the extent to which an intervention is implemented as originally designed" (p 37). There are many factors that influence teacher consultee's treatment integrity. Consultants need to account for these factors when beginning the consultation process (Sanetti \& Kratochwill, 2008). Adding structured follow-up to the consultation process has been shown to increase treatment integrity (Sanetti \& Kratochwill, 2008). 
Due to schools relying on consultation to meet the state and federal requirements of students with problem behavior in complex school environments (Lewis \& Newcomer, 2002) a review of literature on factors that influence treatment integrity was warranted.

\section{Current Demands of Classrooms}

"Working with children, especially children with disruptive behaviors, can be exhausting work" (Egyed \& Short, 2006, p. 465). With the implementation of IDEA (2004), students who were once segregated in the school environment are now spending more time in the general education classroom. This has left general educators with the task of including everyone, including students with more disruptive behaviors, into the daily classroom routines and activities. Oftentimes general educators spend a great amount of time differentiating instruction so that all individuals can be a part of class, which leaves little time to focus on designing and/or implementing behavior treatment plans for students with disabilities (Gansle \& Noell, 2008; Gebbie, Ceglowski, Taylor, \& Miels, 2012). When behavior treatment plans are designed for specific students, they generally have a greater impact on behavior change than just general differentiation. Secondly, with growing classroom sizes, teachers who are already left with minimal planning time, would be overstretched if they were left differentiating for both academics and behavior. In addition to time, general educators often have little to no training when it comes to educating students with behavioral concerns (Shippen et al., 2011).

\section{Consultation}

Professionals often seek the help of experts when presented with challenges in their field. These people are also called consultants (Merriam-Webster's online dictionary, 2013). When a consultant works with another individual, a consultee, on a 
topic area in which the consultee does not have much knowledge, this is called consulting. Consulting can be further defined as providing professional or expert advice (Merriam-Webster.com, 2013). Within the educational literature, there are two types of consultation models researched: instructional consultation (Rosenfield, 1987) and behavioral consultation (Bergan \& Kratochwill, 1990). Both models provide steps for consultants who work with teachers (i.e., consultees) and students in order to improve both academic and behavior skills.

\section{Models of Consultation}

\section{Instructional consultation model.}

The instructional consultation model (Rosenfield, 1987) was introduced to increase pre-referral interventions for students to possibly eliminate the need for a special education referral. Rosenfield (1987) stated that due to the increasing nature of diverse needs of students, teachers may need assistance in providing "quality and adequate instructional programs" (p. 9).

Instructional consultation has three major components: (a) the task, (b) the learner, and (c) the instructional strategies used to teach the learner. Rosenfield (1987) stated that oftentimes a learner is assumed to have a problem and that instruction has been adequate. However, instructional consultation focuses "on the quality and nature of the interaction, which usually is an instructional mismatch" (p. 10).

There are four basic stages to the instructional consultation process: (a) entry and contracting, (b) problem identification, (c) intervention and implementation, and (d) evaluation and termination (Rosenfield, 1987). During "entry and contracting," the consultant prepares the consultee for the overall consultation process and what is 
expected from each person in the consultative relationship. This is done to establish the collaborative relationship at the beginning of the process. During the "problem identification" stage the consultant completes an interview with the teacher to more clearly understand what the problem is, observes the student in the classroom, and completes curriculum-based assessments to further identify the problem in order to indentify appropriate interventions. During "intervention and implementation" the consultant oversees the implementation of interventions by the consultee. The consultant determines if the intervention is implemented correctly and if it is making a difference in the identified problem. During the final phase, "evaluation and termination," the consultant determines if the interventions are to be continued and then leaves written documentation about the consultation and agreed-upon findings.

\section{Behavioral consultation model.}

The behavioral consultation model is based on the principles of operant learning theory and was last revised in 1990 by Bergan and Kratochwill (Segool, Brinkman, \& Carlson, 2007). The model includes four steps: (a) problem identification, (b) problem analysis, (c) treatment implementation, and (d) treatment evaluation. Each of these steps is guided by structured interviews between the consultant and consultee (Bergan \& Kratochwill 1990; Segool et al., 2007). Working through these four steps, the consultant guides the consultee in providing treatment to a client (student) through indirect measures. In a review of the behavioral consultation model, Segool et al. (2007) stated that if a student begins responding to the treatment, the consultee can terminate the consultation process if they feel competent enough to proceed. If the student does not respond or new problems arise, the process usually starts over. While both models of 
consultation are shown to be effective, the research presented in this study is based on the behavioral consultation model. The behavioral consultation model was chosen as the focus due to the focus on students with behavioral concerns within the school setting.

When looking at the service delivery model through which consultation is provided in schools, the majority of the literature focuses on school psychologists or school counselors providing support to teachers. In some districts, consulting services are provided by individuals with a background in special education (Wilkinson, 2003). Other districts may partner with outside companies or universities to provide consultation services to teachers (Chitiyo \& Wheeler, 2009). While each of these models bring positive and negative aspects to the act of consulting, one aspect is clear: IDEA (2004) and its requirement that individual needs of students with disabilities be taken into consideration during educational planning (Shippen et al., 2011) may leave many administrators looking for more support for their teachers.

\section{Behavioral Consultation Process}

\section{Problem identification.}

The first step of the behavioral consultation model is problem identification. During this step, the consultant and consultee meet to discuss the nature of the student's problem and how it relates to a discrepancy between their expected level of performance and where the student is actually performing (Segool et al., 2007). The intent of this step is to objectively define the behavior in measurable and observable terms. This step in the process has been described as the most important step in the consultation process (Wilkinson, 2003). Accurate identification of the behavior targeted for change and identifying it in observable and measureable terms is the stepping stone to developing a 
data collection plan that will be used throughout the consultation process (Bergan \& Kratochwill, 1990; Wilkinson, 2003). Wilkinson (2003) stated that, "consultants should include direct student observation as part of their data collection strategy" (p. 104) during the problem identification stage of the consultation process. By directly observing the student, the consultant does not solely rely on consultee or teacher report of the problem behavior. Teacher perceptions of the behavior may mislead the consultant in the treatment plan development stage, thus making the treatment plan ineffective for the student. Wilkinson also stated that graphing results of direct student observations provides a visual representation of the target behavior which will facilitate interpretation of the behavior over the course of the treatment plan.

\section{Problem analysis.}

Problem analysis is the second step of the behavioral consultation model. During this step, the consultant and consultee "focus on identifying the conditions and variables which influence the behavior" (Segool et al., 2007, p. 312) through functional behavior assessment procedures and interviews. Segool et al. also reported that at the end of the problem analysis step, the consultant uses all of the information gathered to design an appropriate intervention plan for the consultee (teacher) to use with the student.

\section{Plan implementation.}

The third step in the behavioral consultation model is plan implementation, which involves the consultee following through with the intervention plan that was developed during step two of the process (Segool et al., 2007). During the plan implementation step, there are several potential areas where breakdowns within the consultation process can happen. Much of the current literature on consultation has focused around treatment 
integrity. Lane, Bocian, MacMillan, and Gresham (2004) define treatment integrity as "the extent to which an intervention is implemented as originally designed" ( $p$ 37). There are many aspects that have been researched on treatment integrity during consultation. Some, but not all, of these include: (a) consultant leadership style (Kelleher, RileyTillman, \& Power, 2008; Tysinger, Tysinger, \& Diamanduros, 2009), (b) consultee and consultant skill level (Gettinger, Stoiber, \& Koscik, 2008; Lewis \& Newcomer, 2002; Sterling-Turner, Watson, \& Moore, 2002; Wilkinson, 2003), (c) social power strategies (Getty \& Erchul, 2009; Wilson, Erchul, \& Raven, 2008), (d) acceptability of treatment plans (Chitiyo \& Wheeler, 2009; Kelleher, et al., 2008; Noell et al., 2005; Sanetti \& Kratochwill, 2008; Segool, et al., 2007; Tysinger, et al., 2009; Wilkinson, 2003), (e) time of consultant and teacher to implement the intervention (Gansle \& Noell, 2008; Gonzalez, Nelson, Gutkin, \& Shwery, 2004; Lane, et al., 2004; Sanetti \& Kratochwill, 2008), and (f) training provided to consultee (Sanetti \& Kratochwill, 2008; SterlingTurner et al., 2002). When treatment integrity is not assessed during the consultation process, behavior change cannot be fully attributed to the effectiveness of the treatment plan (Lane et al., 2004).

Consultant follow-up is another area that affects treatment plan implementation. The behavioral consultation model does not have specific guidelines for consultant follow-up (Wilkinson, 2006, 2007). It has been shown that the type of follow-up given to consultees during this step can greatly affect the level of treatment integrity. Topics related to follow-up that can be found in the literature include: (a) types and frequency of meetings (Easton \& Erchul, 2011; Noell et al., 2005), (b) performance feedback options (Easton \& Erchul, 2011; Gansle \& Noell, 2008; Mesa, Lewis-Palmer, \& Reinke; 2005; 
Noell, Duhon, Gatti, \& Connell, 2002; Noell et. al., 2005), (c) teacher self-reporting (Sanetti \& Kratochwill, 2009, 2011), and (d) structured interview techniques (Wilkinson, 2006, 2007). Consultants must work with teachers to determine the type of follow-up that will be most effective in ensuring treatment integrity.

\section{Treatment evaluation.}

The fourth step of the behavioral consultation process is treatment evaluation. During this stage, consultant and consultee meet to discuss how effective the implemented treatment plan was at changing student behavior (Segool et al., 2007). Data collected throughout treatment plan implementation are analyzed and compared to data from the initial problem identification and analysis steps. The data will be used to determine if goals set forth in the beginning of the process have been met. If the goal(s) have been met, then treatment may often be terminated and the consultation process concluded. Segool et al. (2007) stated if new problems had arisen or goals had not been met, then the process may revert back to the problem analysis step. If goals had not been met but the student was responding to treatment, consultation could continue or the consultee could terminate the consultation process and continue with the treatment on their own. Segool et al. (2007) stated that data collection is paramount for the final step in the behavioral consultation process to be effective. If good data collection procedures were not put in place, the treatment evaluation phase would not be productive.

\section{Behavioral Consultation and Treatment Integrity}

Within the behavioral consultation framework's four steps to the consultation process, there are many areas where the process can be interrupted. These interruptions can be the responsibility of either the consultant or the consultee. The consultant can 
become frustrated with the process and experience less job satisfaction overtime and rate both themselves and the consultee in a negative light (Cautilli, Tillman, Axelrod, Dziewolska, \& Hineline, 2006). When consultative relationships begin, it is essential for consultants to plan for and attempt to eliminate factors that lead to decreased treatment integrity (Sanetti \& Kratochwill, 2008). Each of the factors that affect treatment integrity during consultation are discussed in the remainder of this paper.

\section{Conclusion}

Both instructional (Rosenfield, 1987) and behavioral consultation (Bergan \& Kratochwill, 1990) are highly researched in the field of education. Behavioral consultation (Bergan \& Kratochwill, 1990) was the focus in the statement of the problem due to its step-by-step process in order to determine appropriate treatment plans for students' with behavioral concerns. When peer consultants work with teachers to develop intervention plans for students with behavioral concerns, there are many aspects that need to be considered. One major aspect that should be considered is treatment integrity of the programs once they are implemented. The following chapter covers several aspects that may influence teachers' treatment integrity of intervention plans developed through peer consultation. 


\section{CHAPTER II}

\section{REVIEW OF RELATED LITERATURE}

Many schools are turning toward a model of consultation to meet the diverse needs of students within their programs. Consultation can be effective in meeting students' academic (Rosenfield, 1987) and behavioral (Bergan \& Kratochwill, 1990) needs. However, consultation is only effective when teachers (i.e., consultees) implement treatment plans developed through consultation with integrity (Noell et al., $2005 \&$ Sanetti \& Kratochwill, 2008). Treatment integrity has been defined as "the extent to which an intervention is implemented as originally designed" (Lane, et al., 2004, p 37). There are many factors that influence teacher consultee's treatment integrity. Some of these factors include consultation style, consultee skill level, treatment plan acceptance, and time available for the consultation process. Consultants need to account for these factors when beginning the consultation process (Sanetti \& Kratochwill, 2008). Adding structured follow-up to the consultation process has been shown to increase treatment integrity (Sanetti \& Kratochwill, 2008).

The Eric EBSCO database was accessed through Illinois State University’s Milner Library to search for supporting literature. The following terms were used during the search of the database: teacher efficacy, special education, teacher consulting, teacher coaching, teacher mentoring, educational consulting, consultation, behavior, education, teacher expectations, consultation methods, teacher perceptions, treatment 
integrity, and student behavior. Limits for peer reviewed articles and the years 20002013 were used in all searches. Seminal works for three concepts were located: (a) social power, (b) behavioral consultation, and (c) instructional consultation. Seminal works on social power were included due to an initial finding related to school consultation. While there was little information directly linking social power to treatment integrity, works were included due to the overall relationship of social power strategies with the relationship between consultants and consultees during the consultation process. Articles with findings from foreign countries were eliminated from the search due to possible differences in pedagogical nature from the United States. After locating an abundance of information on consultation, articles related to coaching and teacher mentoring were also eliminated from the review in order to not inundate the review with information not directly related to the specific topic under review.

\section{Factors that Influence Treatment Integrity}

\section{Leadership Style}

The type of leadership style a consultant uses during consultation can influence how the relationship develops during the behavioral consultation process (Kelleher, et al., 2008; Tysinger et al., 2009). Kelleher et al. (2008) explored the use of partnership-based and expert-driven consultation styles and the overall success of treatment plans each model produced. They found that treatment plans developed in the partnership-based style were implemented with greater levels of treatment integrity than those developed in the expert-driven style. This suggests that consultants should use a collaborative style approach when working with a consultee on developing treatment plans. When 
consultees are included in the development of treatment plans, a positive effect on treatment integrity has been demonstrated (Kelleher, et al., 2008).

Tysinger et al. (2009) also explored the use of collaborative-directive and collaborative-nondirective leadership styles during consultation sessions. The collaborative-directive approach was used when a consultant: (a) was prescriptive, (b) settled disputes, (c) used interpersonal influence techniques, and (d) was respectful of consultees' rights to reject ideas. The collaborative-nondirective approach was used when a consultant: (a) assisted consultees develop their own solutions, (b) attempted to minimize their own control over the sessions, and (c) let consultees lead throughout the process. The authors reported that teachers who viewed videotaped sessions preferred consultants who portrayed the directive approach over the nondirective approach. Both of the consultation sessions in the Tysinger et al. (2009) study were collaborative in nature and included input from the consultee in the process. However, a consultant who allowed input from the consultee, but who also displayed expert knowledge through a directive approach was preferred in this study.

The results of both studies on consultant style suggested that consultees preferred a consultant who included them in the process of developing intervention plans. However, Tysinger et al. (2009) reported that while consultees preferred to be included in the process, they still expected a consultant to bring expert knowledge to the consultative relationship. This translated into a hypothesis by the authors that consultees would implement intervention plans with higher treatment integrity when developed with consultants who they believed had expert knowledge. Tysinger et al. (2009) also 
hypothesized that this may lead consultees to seek out future consultation services in order to provide positive experiences for their students.

\section{Skill Level}

Wilkinson (2003) cited consultee skill level as a factor influencing treatment integrity during consultation. Consultants need to be aware that consultees bring varying degrees of knowledge and skill level to the consultative relationship. If a consultant relied solely on consultee verbal report of their perceived skill level when implementing an intervention, it may lead to lessened treatment integrity and little to no change in target behaviors (Sterling-Turner et al., 2002). This is an additional reason why a collaborative relationship during the consultation process is important. This would give the consultee the opportunity to tell the consultant if they are unfamiliar with a technique and would need more training.

The consultant's skill level is another area that can affect the consultation process. Lewis and Newcomer (2002) list consultant skill as a critical feature of effective consultation. "The consultant must possess a level of expertise and fluency in both process and content" (p. 172) in order to be effective during the consultation process with consultees. It has been hypothesized that when a consultant brings a large knowledgebase to the process, the consultee is more apt to follow through with treatment plans designed by the consultant (Tysinger et al., 2009). Often times, consultees reported that their knowledge base and efficacy when dealing with students with problem behaviors was increased through consultation (Gettinger, et al., 2008). This increase in skill can be attributed to working with a consultant who is an expert in their field and has passed on knowledge to the consultee through the act of consultation. 


\section{Social Power Strategies}

There has been research designed to look at social power strategies used by psychologists when acting as consultants. Social power is defined as the "potential of an individual (i.e., agent) to produce a change in another individuals' (i.e., target's) beliefs, attitudes, and/or behavior" (Wilson et al., 2008, p. 101-102). This concept was introduced by French and Raven (1959) and then later revised by Raven (1992, 1993). From the latest revisions, 14 individual social power strategies were introduced into the consultation literature. They were divided into two major categories of soft (5) and hard (6) social power strategies. Three social power strategies were left out of the distinction between soft and hard. Table 1 lists the social power strategies with definitions by category (Raven 1992; Wilson et al., 2008).

Wilson et al. (2008) reviewed types of social power strategies that consultants are more likely to use. Soft social power strategies were reported to be more effective in bringing about teacher change with regards to implementation of behavior change procedures. When consultants used soft social power strategies, consultees were further inclined to follow through with plan implementation. Getty and Erchul (2009) further examined the use of soft social power strategies and the likelihood that consultant gender may influence their use. The authors reported that male psychologists were more likely to use expert power during consultations with teachers than female psychologists. Expert power, while still a soft social power strategy, "involves influence tactics that are quite dominant and assertive in nature" (Getty \& Erchul, 2009, p. 455). The authors stated that male psychologists may prefer this more direct style of communicating when consulting. 
Table 1

Social Power Bases

\begin{tabular}{|c|c|c|}
\hline Social power base & Definition & Distinction \\
\hline Positive expert & $\begin{array}{l}\text { Target complies because the agent is an } \\
\text { expert in the field. }\end{array}$ & Soft \\
\hline Negative expert & $\begin{array}{l}\text { Target does not comply because they assume } \\
\text { that the agent is using expertise in their own } \\
\text { best interest. }\end{array}$ & None \\
\hline Positive referent & $\begin{array}{l}\text { Target complies because they want to be } \\
\text { associated with or viewed as similar to the } \\
\text { agent. }\end{array}$ & Soft \\
\hline Negative referent & $\begin{array}{l}\text { Target does not comply because they do not } \\
\text { want to be associated with or be similar to the } \\
\text { agent. }\end{array}$ & None \\
\hline Impersonal reward & $\begin{array}{l}\text { Target complies because they perceive that } \\
\text { the agent can provide a tangible reward. }\end{array}$ & Hard \\
\hline Personal reward & $\begin{array}{l}\text { Target complies because they believe the } \\
\text { agent will approve of or like them. }\end{array}$ & Soft \\
\hline Impersonal coercion & $\begin{array}{l}\text { Target complies because they perceive that } \\
\text { the agent has the power to punish them. }\end{array}$ & Hard \\
\hline Personal coercion & $\begin{array}{l}\text { Target complies because they believe that the } \\
\text { agent will disapprove of or dislike them. }\end{array}$ & Hard \\
\hline
\end{tabular}




\begin{tabular}{llc}
\hline Social power base & \multicolumn{1}{c}{ Definition } & Distinction \\
\hline Indirect & Target complies because they hear from & None \\
& $\begin{array}{l}\text { another source how well a particular course } \\
\text { of action worked in a similar situation. }\end{array}$ & \\
Legitimate position & Target complies because the agent holds a & Hard \\
Legitimacy of & position of authority. & Hard \\
reciprocity & something positive for the target. & Hard \\
Legitimacy of equity & Target complies as a way to compensate for & \\
& previous work or suffering on part of the & Soft \\
Legitimacy of & Tagent. & \\
Tependence & to do it themselves. &
\end{tabular}

Note. Raven 1992; Wilson et al., 2008

\section{Consultee Acceptance of Treatment Plans}

Recent research regarding treatment integrity in the consultation process has focused on consultee acceptance of either the treatment plan or consultative process. Kelleher et al. (2008) stated that improved implementation of a treatment plan may be enhanced by consultee choice in the overall consultative process. Treatment integrity is lessened if consultee's did not believe they had the skills to implement the plan or believed that the plan would not be effective. Similar findings have been found in other studies related to acceptability of treatment plans and treatment integrity (Wilkinson, 2003; Segool et al., 2007). 
Similar findings have been found related to consultee expectations and acceptance of the overall consultative process and treatment integrity. Tysinger et al. (2009) stated that the consultative process can by positively influenced by taking a few minutes at the beginning to either formally or informally assess the consultee's expectations. By assessing perceived outcomes at the beginning of the process, the consultant can be aware of any issues that may be present in the beginning instead of having to backtrack in the future. This assessment can also positively influence the outcomes of the relationship; namely treatment integrity can be increased (Tynsinger et al., 2009). Similarly, if teachers are given a leading role in the consultation process, this can lead to more teacher buy-in and promote successful adoption of treatment plan implementation (Chitiyo \& Wheeler, 2009).

While most of the existing research suggests that treatment acceptability enhances treatment integrity, a few studies have refuted that it has much influence (Sanetti \& Kratochwill, 2008; Noell et al., 2005). Noell et al. (2005) found when teachers rated treatments as acceptable; they did not implement them to a substantial degree of treatment integrity. This supported the statement that "acceptability is not sufficient to assure implementation" (p. 102). In a review of current research on treatment integrity in behavioral consultation, Sanetti and Kratochwill (2008) reported that there did not seem to be a direct link between treatment acceptability and treatment plan implementation. The authors supported the view that many factors influenced treatment plan implementation. For instance, if a consultee found a treatment plan acceptable but did not have the resources or skills in order to implement it, this could lead to lessened 
treatment integrity. On the contrary, a consultee may not fully support a treatment plan but would implement it because they felt accountable to do so.

\section{Time}

Today’s schools are very busy places with many different activities happening at one time in the classroom (Gebbie, et al., 2012). Teachers have many different demands competing for their time within the school day, which leads to difficulty implementing treatment plans with high levels of integrity (Gansle \& Noell, 2008). When a consultant is not regularly in the school building, teachers may not seek out consultation services because they do not feel the consultant is available to help them (Gonzalez, et al., 2004). Furthermore, if consultees and consultants cannot find the time to meet together and discuss treatment plan implementation and resulting questions, treatment integrity can be negatively affected.

Time can also be a factor in the delivery of treatment plans. Oftentimes, not only does the teacher have many competing demands within the school day (Gansle \& Noell, 2008), but the complexity of the treatment plan can also be time consuming. Generally speaking, the more complex the intervention is, the more time it will take to implement (Sanetti \& Kratochwill, 2008). When the complexity and time requirement for a treatment plan increases, the level of treatment integrity decreases (Lane et al., 2004).

\section{Training}

According to the review of literature of consultation by Sanetti and Kratochwill (2008), there is little research on the influence of consultee training on treatment integrity. However, the authors stated that training might improve treatment integrity, but more research is needed to prove its effectiveness. Sterling-Turner et al. (2002) 
examined the difference in treatment integrity between indirect and direct training methods. The authors described indirect training methods as didactic (i.e., verbal) instruction and/or being provided with written materials describing the intervention. Direct training methods consisted of modeling, role playing, rehearsal and feedback. Direct training methods offered consultees the ability to practice their skills in the presence of the consultant and receive feedback on their performance. The authors found that consultees were more likely to reach competency levels with direct training methods. The authors also reported that direct training methods led to improved treatment integrity for all teachers.

When considering the number of factors that can affect treatment integrity, consultants must be highly skilled in order to account for them when designing treatment plans for students with behavior concerns (Sanetti \& Kratochwill, 2008). Several strategies for making treatment plans more sound while increasing treatment integrity have been examined. Consultant follow-up to treatment plan implementation is a step that is not well defined within the original behavioral consultation model (Wilkinson, 2006, 2007). This added feature to plan implementation has been shown to lead to greater treatment integrity during the consultation process.

\section{Consultant Follow-up Strategies}

\section{Meetings.}

Because there is no structured follow-up within the behavioral consultation model, (Wilkinson, 2006, 2007) consultants are left to determine how often they should meet with consultee's to provide follow-up to treatment plan implementation. Easton and Erchul (2011) explored teachers' acceptability of monitoring and feedback methods for 
consultation. They reported that teachers found once a week data collection and followup acceptable. Teachers also preferred meeting one-on-one to discuss intervention plan implementation. However, Noell et al. (2005) reported that weekly follow-up was not sufficient to maintain treatment plan implementation unless it involved reviewing implementation data with the consultee. Follow-up meetings should be focused around problem solving and review of student data in order to make an impact on treatment integrity (Noell et al.).

\section{Performance feedback.}

In conjunction with structured meetings between consultants and consultees throughout the consultation process, adding a performance feedback option to meetings is often suggested (Noell et al., 2005). Several researchers have studied how performance feedback impacts treatment plan implementation and integrity. While reviewing student data in meetings is a positive step, it has not been associated with significant improvements in treatment integrity (Noell et al., 2002). Performance feedback includes not only a review of student data, but reviewing plan implementation, steps implemented correctly by the teacher, discussing missed or uncompleted steps, and finally how to improve overall implementation (Noell et al., 2002, Noell et al., 2005).

Performance feedback has been shown to positively affect both student behavior and teacher implementation of treatment plans (Gansle \& Noell, 2008). Simply reviewing student data does not impact treatment integrity as positively as combining it with the other aspects of performance feedback (Noell et al., 2002, Noell et al., 2005). However, Mesa et al. (2005) found that using a line graph was effective at increasing teacher praise for a whole classroom behavior intervention. This suggests that a visual 
representation of the target behavior may further aid in performance feedback and positively influence treatment integrity. Giving consultees positive feedback on steps of the intervention plan implemented correctly also positively influenced treatment integrity (Noell et al., 2005). Having an open discussion about the importance of steps completed incorrectly during performance feedback sessions between consultants and consultees aided in the intervention plan being implemented correctly in future sessions (Noell et al., 2005). Providing performance feedback frequently throughout the intervention process allowed treatment integrity to be monitored closely.

While performance feedback has been shown to positively increase treatment integrity, the frequency and type of feedback given should be considered. In a study by Easton and Erchul (2011), teachers admitted needing regular and consistent feedback on their implementation of treatment programs, but reported having anxiety when consultants came into the classroom to observe their implementation of the plan. Direct observation has been shown to be an important aspect of monitoring treatment integrity (Sanetti \& Kratochwill, 2008), but if teachers reported having anxiety during observations, data collected may not be representative of true plan implementation. Easton and Erchul (2011) reported that teachers preferred submitting permanent product records (e.g., checklists) to consultants for treatment integrity monitoring. The authors also reported teachers viewed practicing missed steps as "slightly punitive" (p. 68). Teachers preferred to plan for future problems and/or discuss encountered problems over practicing missed steps. The authors found that using an action-oriented approach of setting goals for the consultee was a preferred outcome of performance feedback sessions. 
Research supports that performance feedback positively impacted treatment integrity within the plan implementation step of the consultation process. However, reviewing student data is not enough to support high levels of treatment integrity (Noell et al., 2002). Consultees are still learning during the consultation process and performance feedback can foster improvement in treatment plan implementation and integrity. Consultants must remember not to make sessions punitive in nature, but rather action-oriented to promote positive outcomes for all parties involved in the consultation process (Easton \& Erchul, 2011).

\section{Teacher self-report.}

Sanetti and Kratochwill $(2009,2011)$ examined adding a teacher self-report to the consultation process to track treatment integrity during plan implementation. Specifically, they researched the use of the Treatment Integrity Planning Protocol (TIPP). The TIPP is an instrument that is completed jointly by the consultant and consultee during the problem analysis stage of the behavioral consultation model.

The TIPP has 17 questions that are divided into three stages. During Stage I, the focus is on defining the intervention with attention to planning the implementation of intervention steps within the context and culture of the implementation site. During Stage II, the focus shifts to collaboratively planning the treatment integrity assessment and determining assessments for specific required consultee and client behavior as well as logistics of and deviations from intervention implementation. During Stage III, a treatment integrity self-assessment is created from the results of the previous stages (Sanetti \& Kratochwill, 2009, p. 25). 
Specifically, stage three of the TIPP process was shown to be instrumental in increasing treatment integrity during the treatment plan implementation step (Sanetti \& Kratochwill, 2009). Teachers were accurate recorders of their own behavior and reported the selfreport checklist to be feasible and easy to use (Sanetti \& Kratochwill, 2009). By being a collaborative partner in determining which steps of the implementation process were most important to plan implementation, teachers took ownership of the treatment plan and its implementation. Teacher self-report coincided with the action-oriented approach described by Sanetti and Kratochwill (2008) that increased the acceptability of performance feedback sessions.

\section{Structured interviews.}

Wilkinson $(2006,2007)$ reported that adding a fifth step to the traditional behavioral consultation model was warranted. He reported the added step would increase treatment integrity and provide a formal avenue for consultants to follow up with consultees (Wilkinson, 2006, 2007). The added step, the Treatment Monitoring Interview (TMI), follows the treatment plan implementation step. The primary objective of the TMI is to increase the strength of the treatment plan by providing structured follow up. The structured interview would: (a) review the student's behavioral progress, (b) identify barriers or obstacles to the plan's implementation, and (c) determine the need for any modifications to the plan (Wilkinson, 2006). After the structured interview, a performance feedback session is held to further analyze data and provide specific feedback and/or praise for steps of the implementation plan. One caution Wilkinson (2006, 2007) noted was adding a fifth step to an already labor-intensive process may be unrealistic for some consultants and consultees. However, when structured follow up 
sessions were incorporated into the consultation process, increased treatment integrity was demonstrated (Sanetti \& Kratochwill, 2009).

\section{Student Outcomes}

Recently, researchers have begun examining the relationship between treatment integrity and student outcomes. One would assume that higher treatment integrity would be tied to better student outcomes. This assumption has been reported in recent literature (Noell et al., 2005 \& Sanetti \& Kratochwill, 2008) but other findings have been variable (Sterling-Turner et al., 2002). Students have demonstrated behavior change with low to moderate levels of teacher treatment integrity (Sterling-Turner et al., 2002) which leads researchers to believe that there are many variables that may affect student outcomes with regards to treatment plan implementation. In this situation, consultees may implement the treatment components that are most important to student outcomes, which had a positive effect on overall behavior change of the student (Sanetti \& Kratochwill, 2008). Treatment integrity and how it relates to student outcomes is an area that is still being researched in the educational research literature. Future findings on this topic are very relevant to determining best practices for consultant follow up within the behavioral consultation model.

\section{Conclusion and Research Gap}

Treatment integrity within the behavioral consultation model is a crucial factor in determining the effectiveness of the overall process and treatment plan implementation. Several factors were discussed that can either positively or negatively affect plan implementation and resulting treatment integrity. Consultants have the large task of not only collaborating with consultees during the consultation process, but also to account for 
variables that could impact the consultative relationship (Sanetti \& Kratochwill, 2008).

These factors greatly account for the overall effectiveness of the consultation process and the resulting treatment plans designed for affecting student behavior. But which factors are most important to consider when thinking about consultee follow-through within the educational setting? Most of the current literature has focused on psychologists and school counselors as the primary agents in the consultation delivery process. There is little research on factors that affect treatment integrity during educational consultation provided by peer educational consultants (e.g., holding teaching certificates) by consultees.

\section{Research Purpose and Questions}

The purpose of this study is to explore factors that influence teacher treatment integrity of intervention plans for students with behavioral concerns developed through consultation with peer educational consultants.

\section{Questions.}

1. What factors do teachers rate as important during the peer educational consultation process?

2. Do teacher consultee's perceive peer educational consultants as having more knowledge in the area of assessing and planning behavioral interventions for students in their classroom?

These research questions will be answered through a survey of current regular and special education teachers employed within a local special education cooperative.

The findings from this study will impact the Special Education Association of Peoria County (SEAPCO) and how it currently delivers peer consultation to 17 districts 
within their cooperative. SEAPCO consultants report that teacher treatment integrity within their current consultation service delivery model is unaccounted for and is difficult to manage. Consultants have been provided with professional development on different models of consultation delivery, but none have been reported to be successful for each of the consultants. If factors that affect treatment integrity can be identified, SEAPCO consultants can account for those that impact teachers in their service area. Improvement within SEAPCO's consultation service delivery model will positively impact both teachers and students being served through a consultative relationship.

The findings from the current study may also impact the larger field of special education in relation to schools providing consultation services for students in their programs. Treatment integrity needs to be accounted for during the consultation process if treatment plans are to be effective for the students for which they were designed. In determining which factors most greatly impact treatment integrity, according to teachers' perceptions, consultants can plan and account for those factors in the beginning of the consultative relationship. When accounted for, the consultative relationship can be a positive experience for everyone involved. 


\section{CHAPTER III METHODOLOGY}

There are many factors that affect treatment integrity within consultative relationships. When consultants can identify and account for those factors that impact the consultative relationship, treatment plans may be more effective at changing behavior for students. The purpose of this study is to explore factors that influence teacher treatment integrity of intervention plans for students with behavioral concerns developed through consultation with peer educational consultants. The following research questions, research design, participants, instrumentation, procedures, and description of data analyses provided a framework for the study.

\section{Research Questions}

The research questions that guided the study are related to teachers' perceptions of factors that influence their treatment integrity of intervention plans developed through peer consultation. The following questions were answered through a quantitative survey:

1. What factors do teachers rate as important during the peer educational consultation process?

2. Do teacher consultee's perceive peer educational consultants as having more knowledge in the area of assessing and planning behavioral interventions for students in their classroom? 


\section{Research Design}

A quantitative survey design was used for the current study.

\section{Setting}

For the purposes of this study, a special education cooperative from a Midwestern state was selected because it supported its member districts through a peer consultation model. Results from the current study will be used to improve and/or modify the current model of service delivery within the special education cooperative.

\section{Participants}

A convenience sampling method was used to select participants to complete the survey. All participants were teachers that were employed within member districts of the Special Education of Association of Peoria County (SEAPCO), which is a special education cooperative located in Central Illinois. Publically listed emails for teachers were gathered from school websites. Both special education and regular education teachers with publically listed emails were sent the link to complete the survey in this study. Teachers who taught special classes (i.e., physical education, art, music, etc.) were excluded from the current study. Approximately 794 emails were garnered for use within the current study. Twenty-two emails were returned as "undeliverable." There were 136 surveys initially returned for the study. Of the surveys returned, 1 participant did not give consent to participate in the survey, 21 were empty, and 8 only had information related to demographics completed. This left the total number of surveys usable for the current study as $106(\mathrm{~N}=106)$. This makes the return rate for this study $13.35 \%$. Table 2 lists all demographic information asked of participants in the current study. In this study, $23(21.7 \%)$ of the participants had a bachelor's degree, $22(20.8 \%)$ had a bachelor's 
degree plus, $28(26.4 \%)$ had a graduate degree, $33(31 / 1 \%)$ held a graduate degree plus, and 0 reported having earned a doctorate degree. The majority of the participants $(\mathrm{N}=101,95.3 \%)$ reported their ethnicity as white, $2(1.9 \%)$ reported as black or African American, $2(1.9 \%)$ reported as Hispanic or Latino, and $1(.9 \%)$ reported as other. The majority of participants $(\mathrm{N}=93,87.7 \%)$ also reported their gender as female, while 12 $(11.3 \%)$ reported their gender as male. One participant failed to answer this question. A total of $13(12.3 \%)$ participants had been teaching between $0-3$ years, 11 (10.4\%) for 3-5 years, $23(21.7 \%)$ for $6-10$ years, $18(17.0 \%)$ for $11-15$ years, $13(12.3 \%)$ for $16-20$ years, and $28(26.4 \%)$ for more than 20 years. A majority of the participants $(\mathrm{N}=61,57.5 \%)$ in this study held general education certifications, 26 (24.5\%) held special education certifications and $19(17.9 \%)$ held dual certifications.

\section{Survey Instrument}

The survey developed for this study was influenced by a survey regarding teacher perceptions of resistance to school-based consultation with school psychologists in Iowa (Gonzalez et al., 2004). Five of the survey questions were adapted directly from the Gonzalez et al. (2004) survey which served as a guide to design the original questions for the survey used in the current study. Evaluating Factors that Influence Treatment Integrity During Consultation (See Appendix A) was the final instrument developed for use in the current study. Evaluating Factors that Influence Treatment Integrity During Consultation focused on teacher perceptions of treatment integrity of treatment plans developed through peer consultation and consisted of two parts. In part one, respondents were asked to respond to demographic questions on highest level of educational attainment, ethnicity, gender, number of years teaching, what type of teaching certificate 
they held, whether they were a cooperative hired employee, and if they had previously worked with a peer-educational consultant.

Table 2

Demographic Information

\begin{tabular}{|c|c|c|c|}
\hline Demographics & & $\mathrm{n}$ & $\%$ \\
\hline \multirow[t]{5}{*}{ Highest Degree } & Bachelor's & 23 & 21.7 \\
\hline & Bachelor's + & 22 & 20.8 \\
\hline & Graduate & 28 & 26.4 \\
\hline & Graduate + & 33 & 31.1 \\
\hline & Doctorate & - & - \\
\hline \multirow[t]{11}{*}{ Ethnicity } & White & 101 & 95.3 \\
\hline & Black or African & 2 & 1.9 \\
\hline & American & & \\
\hline & American Indian or & - & - \\
\hline & Alaska Native & & \\
\hline & Asian & - & - \\
\hline & Native Hawaiian or & - & - \\
\hline & Other Pacific & & \\
\hline & Islander & & \\
\hline & Hispanic or Latino & 2 & 1.9 \\
\hline & Other & 1 & .9 \\
\hline
\end{tabular}




\begin{tabular}{llcc}
\hline Gender & Female & 93 & 87.7 \\
& Male & 12 & 11.3 \\
Missing & 1 & .9 \\
Years Experience & 0-3 Years & 13 & 12.3 \\
& 3-5 Years & 11 & 10.4 \\
& 6-10 Years & 23 & 21.7 \\
& 11-15 Years & 18 & 17.0 \\
& 16-20 Years & 13 & 12.3 \\
20+ Years & 28 & 26.4 \\
General Education & 61 & 57.5 \\
Special Education & 26 & 24.5 \\
& Dual Certification & 19 & 17.9 \\
\hline
\end{tabular}

Part two of the survey had two options for the respondent to complete.

Determination of which option respondents completed for part two was based on the final question in part one, "Have you had previous contact/working experience with a peer educational consultant?" If respondents answered, "yes" to the final question in part one, wording for statements were worded in the past tense (e.g., "The consultant brought expert knowledge in the area of behavior"). If respondents answered, "no" to the final question in part one, wording for statements were worded in the future tense (e.g., "The consultant should have expert knowledge in the area of behavior").

In part two, respondents were asked to rank their level of agreement with statements regarding peer educational consultation using a 5 -point Likert scale $(0=\mathrm{N} / \mathrm{A}$, 
$1=$ strongly disagree, $2=$ disagree, $3=$ neutral, $4=$ agree, $5=$ strongly agree). There was one closed-ended question in part 2 for respondents who had previously worked with a peer educational consultant (e.g. "How often did your consultant meet with you during the implementation of the treatment plan?"). Survey items in part 2 were from a total of 8 categories developed through a literature review of current practices related to behavioral consultation. The 8 categories are as follows: consultant's job role, consultant interpersonal/relationship skills, adequacy of time available for consultation, consultant follow-up strategies, training provided, teacher efficacy, treatment plan acceptability, and overall perceptions of consultation process.

\section{Procedure}

Consent to perform the research was obtained by the Illinois State University Institutional Review Board (IRB). The respondents of the current study were sent an email containing a cover letter describing the purpose of the study, the time required to complete the survey, potential risks for completing the survey, a measure of confidentiality, and that completion of the survey was voluntary. Contact information in regards to questions about participation in the study was also given (See Appendix B). Once respondents followed the online link, they were presented with an additional cover letter as well as informed consent for participating in the current study. If respondents gave consent to participate in the study, they were directed to the beginning of the survey.

\section{Data Analyses}

Data from the survey instrument were coded and entered into the Statistical Package for Social Sciences, Version 20.0 (SPSS) and descriptive statistics were completed. In order to answer research question one, data were interpreted by analyzing 
the mean response for all respondents, then for respondents with previous contact with a consultant, and finally for respondents with no previous contact with a consultant. In order to answer research question two, data were interpreted by looking at the frequency of all respondents ratings for a specific statement relating to consultant expert knowledge. Data were then further interpreted by analyzing Pearson correlation levels between the expert knowledge statement and four statements that reflected expert knowledge. 


\section{CHAPTER IV}

\section{RESULTS}

Today's teachers are tasked with meeting the needs of very diverse learners within their classroom environment. Many schools are moving toward a consultation model in order to help teachers meet the needs of those diverse learners. Intervention programs developed through consultation can only be effective if they are implemented with treatment integrity (Noell et al., 2005; Sanetti \& Kratochwill, 2008). There are many factors that influence the treatment integrity of treatment plans developed through peer educational consultation. This study was designed to determine which factors teachers from a Midwest special education cooperative rated as important during peer educational consultation.

\section{Findings}

The findings of the study are presented in this chapter. First the findings will be presented for all survey questions answered by respondents. Next the findings will be organized according to the research questions.

Table 3 represents the findings for all survey questions answered by the respondents. 
Table 3

Combined Survey Question Response Percentages

\begin{tabular}{llllllll}
\hline Factor & 0 & 1 & 2 & 3 & 4 & 5 & Missing
\end{tabular}

\section{Knowledge in}

behavior

0

2.8

1.9

7.5

$37.7 \quad 50.0$

0

Consultant

accessibility

0

1.9

7.5

$\begin{array}{lll}8.5 & 46.2 \quad 34.0\end{array}$

Observation of

students

0

2.8

.9

4.7

38.7

52.8

0

Regular follow-

up

0

2.8

5.7

$\begin{array}{lll}1.9 & 55.7 & 33.0\end{array}$

.9

Established

rapport

0

1.9

2.8

$3.8 \quad 52.8$

37.7

.9

Respect for

teaching

practices

0

2.8

.9

6.6

44.3

45.3

0

Supportive

0

1.9

2.8

6.6

41.5

47.2

0

Collaborative

0

2.8

1.9

2.8

$42.5 \quad 50.0$

0

Efficient use of

time

0

1.9

4.7

8.5

37.7

47.2

0

Reviewed data

5.7

.9

8.5

8.5

49.1

26.4

.9

Made changes

from concerns

$2.8 \quad 2.8$

3.8

14.2

59.4

16.0

.9 


\begin{tabular}{lccccccc}
\hline Factor & 0 & 1 & 2 & 3 & 4 & 5 & Missing \\
\hline Incorrect & & & & & & & \\
Implementation & 9.4 & 1.9 & 8.5 & 13.2 & 39.6 & 26.4 & .9 \\
Overall training & 2.8 & 2.8 & 11.3 & 7.5 & 48.1 & 26.4 & .9 \\
Data training & 5.7 & 1.9 & 12.3 & 10.4 & 50.0 & 18.9 & .9 \\
Further training & 3.8 & 0 & 19.8 & 10.4 & 42.5 & 21.7 & 1.9 \\
Personal & & & & & & & \\
knowledge & 0 & 1.9 & 1.9 & 12.3 & 62.3 & 18.9 & 2.8 \\
Personal & & & & & & & \\
Comfort & 1.9 & 1.9 & 4.7 & 11.3 & 50.0 & 28.3 & 1.9 \\
Creation & & & & & & & \\
Involvement & 2.8 & 0 & 2.8 & 6.6 & 47.2 & 38.7 & 1.9 \\
New learning & 0 & 0 & 4.7 & 15.1 & 54.7 & 23.6 & 1.9 \\
Student benefit & 0 & 0 & 3.8 & 8.5 & 39.6 & 46.2 & 1.9 \\
Personal benefit & 0 & 0 & 4.7 & 11.3 & 50.0 & 32.1 & 1.9 \\
\hline Note. 0 Notapplich & 0 & & & & & & \\
\hline
\end{tabular}

Note. $0=$ Not applicable, $1=$ strongly disagree, $2=$ disagree, $3=$ neutral, $4=$ agree, $5=$ strongly agree

\section{Research Questions}

\section{What factors do teachers rate as important during the peer educational}

process? Findings for this question were determined by running a descriptive analysis of all respondent answers to Part Two of the survey in order to find which questions had a mean equal to or higher than $4(M \geq 4)$. Determination of "importance" was determined by having a mean equal to or higher than $4(M \geq 4)$ because the answers to the questions 
in Part Two were coded as, "agree" equaled four and "strongly agree" equaled five. When $M \geq 4$, respondent combined (both previous contact and no previous contact with consultant) answers were determined to have a positive correlation with the question. As shown in Table 4, combined factor answers with a $M \geq 4$ were: (a) knowledge of behavior $(M=4.30)$, (b) accessibility of consultant $(M=4.05)$, (c) observation of the student $(M=4.38),(\mathrm{d})$ regular follow-up $(M=4.11),(\mathrm{e})$ established rapport $(M=4.23),(\mathrm{f})$ respect for teaching practices $(M=4.28),(\mathrm{g})$ supportive $(M=4.29),(\mathrm{h})$ collaborative $(M=4.35),(\mathrm{i})$ efficient $(M=4.24),(\mathrm{j})$ involvement in treatment plan creation $(M=4.15),(\mathrm{k})$ student benefit $(M=4.31)$, and (1) personal benefit $(M=4.12)$. In total, 12 out of 22 factors had a mean equal to or greater than 4 .

Table 4

Combined Factor Means

\begin{tabular}{lc}
\hline Factor & Mean \\
\hline Knowledge in behavior & 4.30 \\
Consultant accessibility & $\mathbf{4 . 0 5}$ \\
Observation of students & $\mathbf{4 . 3 8}$ \\
Regular follow-up & $\mathbf{4 . 1 1}$ \\
Established rapport & $\mathbf{4 . 2 3}$ \\
Respect for teaching practices & $\mathbf{4 . 2 8}$ \\
Supportive & $\mathbf{4 . 2 9}$ \\
Collaborative & $\mathbf{4 . 3 5}$ \\
Efficient use of time & $\mathbf{4 . 2 4}$ \\
Reviewed data & 3.75 \\
\hline
\end{tabular}




\begin{tabular}{ll}
\hline Factor & Mean \\
\hline Made changes from concerns & 3.74 \\
Incorrect Implementation & 3.52 \\
Overall training & 3.76 \\
Data training & 3.55 \\
Further training & 3.56 \\
Personal knowledge & 3.97 \\
Personal Comfort & 3.94 \\
Creation Involvement & $\mathbf{4 . 1 5}$ \\
New learning & 3.99 \\
Student benefit & $\mathbf{4 . 3 1}$ \\
Personal benefit & $\mathbf{4 . 1 2}$ \\
\hline
\end{tabular}

Next a descriptive analysis was run to determine if respondents who had previous contact with a consultant had different answers than those from the combined factor answers. As shown in Table 5, factors that had a $M \geq 4$ for respondents with previous contact were: (a) knowledge in behavior $(M=4.07)$, (b) observation of the student ( $M=4.23)$, (c) regular follow-up ( $M=4.00)$, (d) established rapport ( $M=4.21)$, (e) respected teaching practices $(M=4.16)$, (f) supportive $(M=4.23),(\mathrm{g})$ collaborative $(M=4.14),(\mathrm{h})$ efficient $(M=4.00)$, (i) personal knowledge $(M=4.13)$, (j) personal comfort $(M=4.11)$, and (k) involvement in treatment plan creation $(M=4.00)$. In total, 11 out of 22 factors had a $M \geq 4$ on the previous contact. Of those 11 factors, 9 were also found with a $M \geq 4$ on 
the combined factors list. This indicated a difference of two factors that were on the previous contact factors list but were not on the combined factors list.

Table 5

Previous Contact Factor Means

\begin{tabular}{ll}
\hline Factor & Mean
\end{tabular}

Knowledge in behavior

Consultant accessibility

Observation of students

Regular follow-up

Established rapport

Respect for teaching practices

Supportive

Collaborative

Efficient use of time

Reviewed data

Made changes from concerns

Incorrect Implementation

Overall training

Data training

Further training

Personal knowledge

Personal Comfort

Creation Involvement
4.07+

4.23+

4.00+

$4.21+$

4.16+

4.23+

4.14+

4.00+

4.13

4.11

4.00+ 
New learning

Student benefit

Personal benefit

\subsection{3}

3.96

3.98

Note. + indicates $M \geq 4$ in both combined factor means and previous contact factor means

Finally a descriptive analysis was run to determine if respondents who had no previous contact with a consultant rated different factors as important as the combined factor answers, as well as the previous contact factor answers. As shown in table 6, factors with a $M \geq 4$ for respondents with no previous contact were: (a) knowledge in behavior ( $M=4.57)$, (b) accessibility of consultant $(M=4.38)$, (c) observation of the student $(M=4.55),(\mathrm{d})$ regular follow up $(M=4.25)$, (e) established rapport $(M=4.24)$, (f) respect for teaching practices $(M=4.43),(\mathrm{g})$ supportive $(M=4.37),(\mathrm{h})$ collaborative $(M=4.59)$, (i) efficient $(M=4.51),(\mathrm{j})$ reviewed data $(M=4.24),(\mathrm{k})$ made changes from concerns $(M=4.00),(1)$ informed of incorrect implementation $(M=4.43),(\mathrm{m})$ overall training $(M=4.43),(\mathrm{n})$ data training $(M=4.24),(\mathrm{o})$ further training $(M=4.31),(\mathrm{p})$ involvement in treatment plan creation $(M=4.33)$, (q) should learn something $(M=4.06)$, (r) student benefit $(M=4.69)$, and (s) personal benefit $(M=4.27)$. In total, 19 out of 22 factors were had a $M \geq 4$. Of those 19 factors, 12 were also found to have a $M \geq 4$ on the combined factor list and 9 were also found to have a $M \geq 4$ on the previous contact factor list. This indicates that expectations of those who have not been through the consultation process may be expecting more out of the process than those who have worked with a consultant previously. 
Table 6

No Previous Contact Factor Means

\begin{tabular}{|c|c|}
\hline Factor & Mean \\
\hline Knowledge in behavior & $4.57++$ \\
\hline Consultant accessibility & $4.38+$ \\
\hline Observation of students & $4.55++$ \\
\hline Regular follow-up & $4.25++$ \\
\hline Established rapport & 4.24++ \\
\hline Respect for teaching practices & 4.43++ \\
\hline Supportive & $4.37++$ \\
\hline Collaborative & $4.59++$ \\
\hline Efficient use of time & $4.51++$ \\
\hline Reviewed data & 4.24 \\
\hline Made changes from concerns & 4.00 \\
\hline Incorrect Implementation & 4.43 \\
\hline Overall training & 4.43 \\
\hline Data training & 4.24 \\
\hline Further training & 4.31 \\
\hline Personal knowledge & 3.80 \\
\hline Personal Comfort & 3.76 \\
\hline Creation Involvement & 4.33++ \\
\hline New learning & $4.06+$ \\
\hline Student benefit & $4.69+$ \\
\hline
\end{tabular}


Note. + indicates $M \geq 4$ in both combined factor means and previous contact factor means ++ indicates $M \geq 4$ in both previous contact means and no previous contact factor means

\section{Do teacher consultee's perceive peer educational consultants as having more}

\section{knowledge in the area of assessing and planning behavioral interventions for students}

in their classroom? Findings for research question two were first determined by looking at the number of respondents who rated the survey statement "The consultant brought/should bring expert knowledge in the area of behavior" positively. The majority of respondents rated this statement positively with 40 out of $106(38 \%)$ agreeing and 53 out of $106(50 \%)$ strongly agreeing with the statement. Only a small percentage of respondents rated the statement negatively with three out of $106(3 \%)$ strongly disagreeing, two out of $106(2 \%)$ disagreeing, and eight out of $106(7.5 \%)$ rating the statement as neutral.

Next, a Pearson Correlation was run to determine if there was a significant correlation between the statement "The consultant brought/should bring expert knowledge in the area of behavior" and four other survey statements thought to reflect a consultant's expert knowledge in the area of behavior. The four statements run in the correlation test were: (a) "The consultant reviewed/should review data from the intervention plan and made/make changes if warranted," (b) "The consultant informed/should inform me of steps that were/are incorrectly implemented during the implementation of the treatment plan," (c) "The consultant provided/should provide 
training regarding overall intervention plan implementation," and (d) "The consultant provided/should provide training regarding how to collect and record data."

Correlations are considered significant if results of the test are .05 or lower $(p \leq$ $.05)$. As seen in table 7, results indicate that all four of the related statements had significant correlations with the statement "The consultant brought/should bring expert knowledge in the area of behavior."

Table 7

Factor Significance Levels

\begin{tabular}{lc}
\hline Factor & $p$ \\
\hline Reviewed data & $.001^{* *}$ \\
Incorrect Implementation & $.000^{* *}$ \\
Overall training & $.000^{* *}$ \\
Data training & $.000^{* *}$ \\
\hline
\end{tabular}

Note. $* * p<.001$

\section{Additional Results}

One additional finding from the current study was the statement indicating if respondents with previous contact would collaborate with a peer educational consultant in the future. A mean analysis was completed and the results indicate that most respondents would collaborate again with a $\mathrm{M}=4.31$. These results are strengthened when combined with correlational data related to both the respondent and student benefiting from the consultation procedure. The following statements indicate a strong correlational relationship between themselves and collaborating again: (a) "I learned/should learn something new through the consultation process", $r(53)=.001, p<$ 
.01 , (b) "The consultation process was/should be beneficial for the student(s)", $r(53)=$ $.000, p<.01$, and (c) "The consultation process was/should be beneficial for me", $r(53)=$ $.000, p<.01$.

Respondents with previous contact also reported that the consultation process was efficient $(M=4.00)$. When paired with expectations of efficiency of those respondents who have not previously worked with a consultant $(M=4.51)$, the current process appears to be meeting those expectations. Finally, ethnicity of respondents was strongly related to personal comfort when implementing behavior supports and strategies within the classroom, $r(104)=.048, p<.05$. If a respondent answered that they were comfortable implementing behavior supports in their classroom, they most likely had given "white" as their ethnicity. 


\section{CHAPTER V \\ SUMMARY, DISCUSSION, IMPLICATIONS, AND RECOMMENDATIONS}

In this final chapter, an overview of the study is presented, including a statement of the problem, research questions, and method. Next, a summary of the results is presented along with a short discussion. Finally, limitations of the study and possibilities for future research are presented.

\section{Overview of the Study}

\section{Statement of the Problem}

Today's schools are tasked with educating learners with diverse instructional and behavioral needs. Many schools are turning toward a model of consultation in order to best provide services to those learners. However, consultation is only effective when teachers (i.e., consultees) implement treatment plans developed through consultation with integrity (Noell et al., 2005; Sanetti \& Kratochwill, 2008). There are many factors that can influence treatment integrity. The current study attempted to identify specific factors that teachers from a Midwestern special education cooperative found important when engaged in peer consultation. 


\section{Purpose of the Study}

The purpose of this study was to explore factors that influence teacher treatment integrity of intervention plans for students with behavioral concerns developed through consultation with peer educational consultants.

\section{Research questions.}

1. What factors do teachers rate as important during the peer educational consultation process?

2. Do teacher consultee's perceive peer educational consultants as having more knowledge in the area of assessing and planning behavioral interventions for students in their classroom?

\section{Method}

\section{Participants}

All participants were teachers that were employed within member districts of the Special Education of Association of Peoria County (SEAPCO), which is a special education cooperative located in Central Illinois.

\section{Survey Instrument}

Evaluating Factors that Influence Treatment Integrity During Consultation was developed for use in this study. The instrument focused on teacher perceptions of treatment integrity of treatment plans developed through peer consultation and consisted of two parts. In part one, respondents were asked to respond to demographic questions. In part two, respondents were asked to rank their level of agreement with statements regarding peer educational consultation using a 5 -point Likert scale $(0=\mathrm{N} / \mathrm{A}, 1=$ strongly disagree, $2=$ disagree, $3=$ neutral, $4=$ agree, $5=$ strongly agree). There was one closed-ended 
question in part 2 for respondents who had previously worked with a peer educational consultant.

\section{Data Analyses}

Data from the survey instrument were coded and entered into the Statistical Package for Social Sciences (SPSS) and descriptive statistics were completed. In order to answer research question one, data were interpreted by analyzing the mean response for all respondents, then for respondents with previous contact with a consultant, and finally for respondents with no previous contact with a consultant. In order to answer research question two, data were interpreted by looking at the frequency of all respondents ratings for a specific statement relating to consultant expert knowledge. Data were then further interpreted by analyzing correlation levels between the expert knowledge statement and four statements that reflected expert knowledge.

\section{Summary and Discussion of Major Findings}

\section{Research Question 1}

This question examined what factors teachers determined important during the consultation process. Combined factor means indicated that 12 out of 22 factors were rated as important during the consultation process. When results were looked at separately between respondents that had previous contact with a consultant and those who did not, the results have some variance. For those individuals with previous contact, 11 factors had a mean greater than or equal to $4(\mathrm{M} \geq 4)$ and for those individuals with no previous contact, 19 factors had a $M \geq 4$. The difference in results between the two groups is most likely attributed to actual experience in the process. Individuals with previous contact answered statements based off of previous experience, while individuals 
without answered statements based off of an "ideal" peer consultation session. Results for this question are consistent with Sanetti and Kratochwill (2008) that reported that there were many factors that may influence treatment integrity.

\section{Research Question 2}

This question examined whether respondents perceived peer educational consultants as having "expert knowledge" in the area of behavior for students in their classrooms. Results for this question were determined by looking at the correlation between statements related to "expert knowledge" in the survey instrument. All correlations were considered highly significant with significance values of less than .001 $(\mathrm{p}<.001)$. These results indicate that teachers do consider a consultant's skill level as important during the consultation process. This is consistent with results from Lewis and Newcomer (2002) and Tysinger et al. (2009).

\section{Additional Results}

Additional results indicated that respondents with previous experience working with a peer consultant would do so in the future. This is a positive outcome for the consultation process for the special education cooperative targeted in this study. The correlational data strengthens this outcome by determining that the process is beneficial for both teachers and students. The results indicate that teacher respondents find the consultation process as a positive addition to the supports they receive when educating students with behavior problems in their classrooms.

A second additional result indicated that there is a strong correlational relationship between a respondent's ethnicity and their comfort level when implementing behavior supports. As a result, consultants may need to take extra care when introducing 
behavior supports to teachers with differing ethnicities. There may need to be changes in terminology or presentation in order to make all individuals comfortable when implementing the behavior supports and changes within the classroom.

\section{Implications for Practice}

The results of the current study identify several areas that peer educational consultants can focus on in order to improve their current service delivery in the area of behavioral consultation. Overall, the results indicate that most teachers view peer educational consultants as having expert knowledge in the area of behavior and behavioral supports. However, there are factors that are not meeting expectations of those individuals who have yet to go through the consultation process. In the current study, there were ten factors that individuals without previous contact felt were important in the consultation process that were not confirmed in the responses from those respondents with previous contact. Those ten factors are: (a) consultant accessibility, (b) data review, (c) making changes from concerns, (d) informed of incorrect implementation, (e) overall training provided, (f) data collection training, (g) offered further training, (h) learning something through consultation, (i) student benefit, and (j) personal benefit. These are factors that current peer educational consultants need to focus on in current and subsequent consultation sessions.

\section{Limitations of the Study}

The current study does have some limitations. One large limitation was the sampling procedure leading to results being confined to a local special education cooperative. The results of the study indicate implications for practice, they are only related to the local cooperative and cannot be generalized. While that was one of the 
purposes of the study, it limits the results to other areas within the state and country that use a similar model of consultation for meeting students' needs. A second limitation of the study was the low return rate. A return rate of $13.35 \%$ does not lend well to generalizability within the cooperative itself. There was some indication of difficulty entering into the survey dependent on the type of internet browser respondents were using, but this was not readily discovered until after the second reminder email was sent out. This may have impacted the return rate as only individuals who contacted the survey administrator were determined enough to search out an option for taking the online survey instrument.

Finally, the persons in this convenience sample may have known the researcher personally and may have felt the need to give more socially appropriate answers to the survey instrument. Conversely, the opposite may be true as well. Respondents may have had a bad experience with the researcher or other consultants and may have answered with lower ratings had the instrument been sent by a different individual.

\section{Recommendations for Future Research}

While the results of this study provide information that can directly impact a local special education cooperative and how they provide peer consultation services to their teachers and students, there are seven more avenues that could be explored in future research.

1. Further the scope of the research by seeking out additional school districts and cooperatives within the local area, state, and surrounding states to determine if results from this study are similar to other areas and if the same factors are valued within the consultation process; 
2. Determine what can be done to increase return rates in future online survey research;

3. Further explore the factors that directly relate to treatment integrity by asking more specific questions related to follow through of treatment plans (e.g. "I implemented the treatment plan as indicated by the consultant");

4. Further explore the breakdown between expectations of those without previous experience and the actual results of those who have participated in the consultation process. This would allow for further determination of whether those who have been through the process do not value the same factors when efficiency and overall benefit are direct results of the process;

5. Consider adding questions to the survey directly related to student eligibility category and intensity of the behavior addressed during the consultation process. If respondents are asked to give more specific information related to the nature of the consultation, they may answer differently to some statements on the survey. This information may impact the overall satisfaction with the consultation process and change the outcomes of the survey results;

6. Consider further analyzing data by matching results with different demographic categories (e.g., did those with same degree level have similar responses to statements regarding the consultant having expert knowledge in behavior); and

7. Consider researching information on coaching in order to enhance the service delivery of consulting services to teachers within the general and special education settings. 


\section{Conclusion}

With many schools using a model of consultation to support teachers in their efforts to educate students with behavior issues in their classrooms, the current study sheds light on factors that may impact the consultative relationship. Teacher respondents from this study reported that consultants have more knowledge in the area of behavior; there are still many factors that may influence the treatment integrity of behavior plans developed through consultation. With results both from teachers, who have had experience with consultation and those who have not, there is guidance for expectations for the overall process and evidence of how those expectations may have not been met. Peer educational consultants should be aware of those factors that do not meet expectations and remedy those in order to make the consultation process more beneficial and efficient for everyone involved. 


\section{REFERENCES}

Bergan, J. R., \& Kratochwill, T. R. (1990). Behavioral consultation and therapy. New York: Plenum Press.

Cautilli, J., Tillman, T. C., Axelrod, S., Dziewolska, H, \& Hineline, P. (2006). Resistance is not futile: An Experimental analogue of the effects of consultee "resistance" on the consultant's therapeutic behavior in the consultation process: A Replication and extension. International Journal of Behavioral and Consultation Therapy, 2(3), 362-374.

Chitiyo, M. \& Wheeler, J. J. (2009). Analyzing the treatment efficacy of a technical assistance model for providing behavioral consultation to schools. Preventing School Failure, 53(2), 85-88. doi:10.3200/psfl.53.2.85-88

Consultant. (n.d.). In Merriam-Webster online. Retrieved June 25, 2013, from http://www.merriam-webster.com/dictionary/consultant.

Consulting. (n.d.). In Merriam-Webster online. Retrieved June 25, 2013, from http://www.merriam-webster.com/dictionary/consulting

Easton, J. E. \& Erchul, W. P. (2011). An exploration of teacher acceptability of treatment plan implementation: Monitoring and feedback methods. Journal of Educational and Psychological Consultation, 21(1), 56-77. doi:10.1080/10474412.2011.544949

Egyed, C. J. \& Short, R. J. (2006). Teacher self-efficacy, burnout, experience, and decision to refer a disruptive student. School Psychology International, 27(4), 462-474. doi:10.1177/0143034306070432

French, J. R. P. Jr. \& Raven, B. (1959). The bases of social power. In D. Cartwright (Ed.), Studies in social power (150-167). Ann Arbor, MI: Institute for Social Research.

Gansle, K. A. \& Noell, G. H. (2008). Consulting with teachers regarding academic skills: Problem solving for basic skills. International Journal of Behavioral Consultation and Therapy, 4(2), 199-211. 
Gebbie, D. H., Ceglowski, D., Taylor, L. K., \& Miels, J. (2012). The role of teacher efficacy in strengthening classroom support for preschool children with disabilities who exhibit challenging behaviors. Early Childhood Education Journal, 40(1), 35-46. doi:10.1007/s10643-011-0486-5

Gettinger, M., Stoiber, K., \& Koscik, R. (2008). Effects of a preparation program focused on accommodating children with challenging behaviors. Teacher Education and Special Education, 31(3), 164-181. doi:10.1177/0888406406408330624

Getty, K. C. \& Erchul, W. P. (2009). The influence of gender on the likelihood of using soft social power strategies in school consultation. Psychology in the Schools, 46(5), 447-458. doi:10.1002/pits.20389

Gonzalez, J. E., Nelson, J. R., Gutkin, T.B., \& Shwery, C. S. (2004). Teacher resistance to school-based consultation with school psychologists: A survey of teacher perceptions. Journal of Emotional and Behavioral Disorders, 12, 30-37.

IBM Corp. Released 2011. IBM SPSS Statistics for Macintosh, Version 20.0. Armonk, NY: IBM Corp.

Individuals with Disabilities Education Act, 20 U.S.C. $§ 1400$ (2004).

Kelleher, C., Riley-Tillman, T. C, \& Power, T. J. (2008). An initial comparison of collaborative and expert-driven consultation on treatment integrity. Journal of Educational and Psychological Consultation, 18(4), 294-324. doi:10.1080/10474410802491040

Lane, K. L., Bocian, K. M., MacMillan, D. L., \& Gresham, F. M. (2004). Treatment integrity: An essential - but often forgotten - component of school-based interventions. Preventing School Failure, 48(3), 36-43. doi:10.3200/psfl.48.3.3643

Lewis, T. J. \& Newcomer, L. L. (2002). Examining the efficacy of school-based consultation: Recommendations for improving outcomes. Child and Family Behavior Therapy, 24(1/2), 165-181. doi:10.1300/Jo19v24n01_11

Mesa, J., Lewis-Palmer, T., \& Reinke, W. (2005). Providing teachers with performance feedback on praise to reduce student problem behavior. Beyond Behavior, 15(1), 3-7.

Noell, G. H., Duhon, G. J., Gatti, S. L, \& Connell, J. E. (2002). Consultation, follow-up, and implementation of behavior management interventions in general education. School Psychology Review, 31(2), 217-234. 
Noell, G. H., Witt, J. C., Slider, N. J., Connell, J. E., Gatti, S. L, Williams, K. L., . . Resetar, J. L. (2005). Treatment implementation following behavioral consultation in schools: A comparison of three follow-up strategies. School Psychology Review, 34(1), 87-106.

Raven, B. H. (1992). A power/interaction model of interpersonal influence: French and Raven thirty years later. Journal of Social Behavior and Personality, 7(2), 217244.

Raven, B. H. (1993). The bases of power: Origins and recent developments. Journal of Social Issues, 49(4), 227-251.

Rosenfield, S. A. (1987). Instructional consultation. New Jersey: Lawrence Erlbaum Associates.

Sanetti, L. M. H. \& Kratochwill, T. R. (2008). Treatment integrity in behavioral consultation: Measurement, promotion, and outcomes. International Journal of Behavioral Consultation and Therapy, 4(1), 95-114.

Sanetti, L. M. H. \& Kratochwill, T. R. (2009). Treatment integrity assessment in the schools: An evaluation of the treatment integrity planning protocol. School Psychology Quarterly, 24(1), 24-35. doi:10.1037/a0015431

Sanetti, L. M. H. \& Kratochwill, T. R. (2011). An evaluation of the treatment integrity planning protocol and two schedules of treatment integrity self-report: Impact on implementation and report accuracy. Journal of Educational and Psychological Consultation, 21(4), 284-308. doi:10.1080/10474412.2011.620927

Segool, N. K., Brinkman, T. M., \& Carlson, J. S. (2007). Enhancing accountability in behavioral consultation through the use of single-case designs. International Journal of Behavioral Consultation and Therapy, 3(2), 310-321.

Shippen, M. E., Flores, M. M., Crites, S. A., Patterson, D., Ramsey, M. L., Hourchins, D. E., \& Jolivette, K. (2011). Classroom structure and teacher efficacy in service students with disabilities: Differences in elementary and secondary teachers. International Journal of Special Education, 26(3), 36-44.

Sterling-Turner, H. E., Watson, T. S., \& Moore, J. W. (2002). The effects of direct training and treatment integrity on treatment outcomes in school consultation. School Psychology Quarterly, 17(1), 47-77. doi:10.1521/scpq.17.1.47.19906

Tysinger, P. D., Tysinger, J. A., \& Diamanduros, T. (2009). Teacher expectations on the directiveness continuum in consultation. Psychology in the Schools, 46(4), 319332. doi: $10.1002 /$ pits. 20378 
Wilkinson, L. A. (2003). Using behavioral consultation to reduce challenging behavior in the classroom. Preventing School Failure, 47(3), 100-105.

doi:10.1080/10459880309604437

Wilkinson, L. A. (2006). Monitoring treatment integrity: An alternative to the 'consult and hope' strategy in school-based behavioural consultation. School Psychology International, 27(4), 426-438. doi:10.1177/0143034306070428

Wilkinson, L. A. (2007). Assessing treatment integrity in behavioral consultation. International Journal of Behavioral Consultation and Therapy, 3(3), 420-432.

Wilson, K. E., Erchul, W. P., \& Raven, B. H. (2008). The likelihood of use of social power strategies by school psychologists when consulting with teachers. Journal of Educational and Psychological Consultation, 18(2), 101-123. doi:10.1080/10474410701864321 


\section{APPENDIX A \\ EVALUATING FACTORS THAT INFLUENCE TREATMENT \\ INTEGRITY DURING CONSULTATION SURVEY}

[This will appear at the beginning of the online survey]

You are being asked to participate in a research study that I am completing under the direction of Dr. Christy Borders in the Department of Special Education at Illinois State University to fulfill the requirements of my Master's degree. This study examines factors influence teachers' treatment integrity of intervention plans for students with behavioral concerns developed through consultation with peer educational consultants.

This survey includes up to 30 questions and will take about 10-15 minutes to complete. Some questions will lead you to another question depending on your experience. The questions ask for demographic information as well as teachers' perspectives on implementing intervention plans for students with behavioral concerns developed through consultation with peer educational consultants.

Your participation is voluntary and all information will be anonymous. No identifying information about you, your location where you are completing this survey, your school, or your specific responses to the questions is collected from your computer nor can it be retained by the online survey system. No identifiable information about you, or provided by you during this research, can be or will be disclosed to others by the researchers. Your name will not be used in any report or presentation in which the results will be discussed. As a participant you are able to withdraw from the survey at anytime.

There are some risks to participating in the survey. There may be a slight risk for discomfort in answering some of the questions because of the topic being explored. However, you may withdraw from the study at any point for any reason by exiting the survey. Responses to surveys that are not completed and submitted are not retained. The district may have software that closely monitors the computer use and activity of students and staff. Because the responses to this survey involve information about aspects of your position, you may wish to complete this survey on a non-work related computer at a 
location other than school if you feel that there is any risk to your employment by completing this survey.

If you have any questions please contact me at 309-202-4549 or jaarms@ilstu.edu or Dr. Christy Borders at 309-438-5829 or christy.borders@illinoisstate.edu. If you have any questions about your rights as a subject/participant in this research, or if you feel you have been placed at risk, you can contact the Research Ethics \& Compliance Office at Illinois State University at (309) 438-2529 and/or rec@ilstu.edu.

Thank you for your time and your consideration of this study.

Sincerely,

Jennifer Arms

Master's Student

Illinois State University

jaarms@ilstu.edu

309-202-4549

Confirmation of Research Subject

I have read and understand the information provided above. I have been given an opportunity to exit this survey to email or call Dr. Christy Borders or Jennifer Arms with questions and have returned to it with any of my questions answered to my satisfaction. By clicking "I give consent to participate", I willingly agree to participate in the research it describes.

\section{Treatment Integrity Survey}

Page 1: Demographics

Please select the answer that best describes your experiences.

\section{What is your highest level of educational attainment?}

- Bacehlor's Degree

- Bachelor's Degree + (not graduate degree)

- Graduate Degree

- $\quad$ Graduate Degree +

- $\quad$ Doctorate Degree 


\section{Ethnicity:}

- White

- $\quad$ Black or African American

- American Indian or Alaska Native

- Asian

- Native Hawaiian or Other Pacific Islander

- Hispanic or Latino

- $\quad$ Other

3. Gender:

- Male

- $\quad$ Female

4. Number of Years Teaching:
- $\quad 0-3$
- $\quad 3-5$
- 6-10
- $\quad 10-15$
- $15-20$
- $20+$

5. I hold a degree in:

- General Education

- Special Education

- Dual Certification

6. Are you a SEAPCO employee?

- Yes

7. Have you had previous contact/working experience with a SEAPCO consultant?
- $\quad$ Yes
- $\quad$ No 


\section{Part 2: Treatment Integrity}

The following statements did (yes previous contact with)/would (no previous contact with) influence my implementation of behavioral interventions developed through consultation

Use 5 point Likert Scale for the following sections. $(0=\mathrm{N} / \mathrm{A}, 1=$ Strongly disagree, $2=$ disagree, $3=$ neutral, $4=$ agree, $5=$ =strong agree $)$

\section{Consultant's Job Role}

1) The consultant brought/should bring expert knowledge in the area of behavior.

2) The consultant was/should be easily accessible to me.

3) The consultant did/should observe students in the classroom.

4) The consultant did/should follow-up with me on a regular basis.

\section{Consultant Interpersonal/Relationship Skills}

5) The consultant $\mathrm{did} /$ should establish rapport with me.

6) The consultant showed respect/should be respectful of my teaching practices.

7) The consultant was/should be supportive of me.

8) The consultant was/should be collaborative.

\section{Adequacy of Time Available for Consulting}

9) Consultation was/should be an efficient use of my time.

\section{Consultant Follow-up Strategies}

10) How often did/should your consultant meet with you during implementation of the treatment plan? (This question will not be Likert)

- Weekly

- Bi-weekly

- Monthly

11) The consultant reviewed/should review data from the intervention plan and made/make changes if warranted.

12) The consultant made/should make changes in the intervention plan based on my concerns.

13) The consultant informed/should inform me of steps that were incorrectly

implemented during implementation of the treatment plan.

\section{Training Provided}

14) The consultant provided/should provide training regarding overall intervention plan implementation.

15) The consultant provided/should provide training regarding how to collect and record data. 
16) I was asked/should be asked if further training or explanation was/is needed before the intervention plan was/is implemented.

\section{Efficacy}

17) I have knowledge/do have knowledge of behavioral supports and strategies.

18) I was comfortable/am comfortable implementing behavioral supports and strategies in my classroom.

\section{Treatment Plan Acceptability}

19) I was/should be involved in the creation of the intervention plan.

\section{Overall perceptions of consultation process-is it beneficial?}

20) I learned/should learn something new through the consultation process.

21) The consultation process was/should be beneficial for the student(s).

22) The consultation process was/should be beneficial for me.

Previous work with SEAPCO consultant (for those who answered yes)

23) I would collaborate with a peer educational consultant again. 


\section{APPENDIX B \\ RECRUITMENT EMAIL}

February 1, 2014

Dear Educator:

I am a master's student under the direction of Dr. Christy Borders in the Department of Special Education at Illinois State University. I am conducting a research study that will determine what factors influence teachers' treatment integrity of intervention plans for students with behavioral concerns developed through consultation with peer educational consultants.

I am requesting your participation in a survey study. The survey includes up to 30 questions and will take about 10-15 minutes to complete. Some questions will lead you to another question depending on your answer. The questions ask for demographic information as well as teachers' perspectives on implementing intervention plans for students with behavioral concerns developed through consultation with peer educational consultants.

Your participation is voluntary and all information will be anonymous. No identifying information about you, your location where you are completing this survey, your school, or your specific responses to the questions is collected from your computer nor can it be retained by the online survey system. No identifiable information about you, or provided by you during this research, can be or will be disclosed to others by the researchers. Your name will not be used in any report or presentation in which the results will be discussed. As a participant, you are able to withdraw from the survey at anytime without penalty.

There are some risks to participating in the survey. There may be a slight risk for discomfort in answering some of the questions because of the topic being explored. However, you may withdraw from the study at any point for any reason by exiting the survey. Responses to surveys that are not completed and submitted are not retained. The district may have software that closely monitors the computer use and activity of students and staff. Because the responses to this survey involve information about aspects of your 
position, you may wish to complete this survey on a non-work related computer at a location other than school if you feel that there is any risk to your employment by completing this survey. We do not anticipate that each participant will have direct benefits from this survey. Some participants may find it helpful for improving their teaching, but others may not.

If you are interested in participating, please go to: (web address) If you have any questions please contact me at 309-202-4549 or jaarms@ilstu.edu or Dr. Christy Borders at 309-438-5829 or christy.borders@illinoisstate.edu.

If you have any questions about your rights as a subject/participant in this research, or if you feel you have been placed at risk, you can contact the Research Ethics \& Compliance Office at Illinois State University at (309) 438-2529 and/or rec@ilstu.edu.

Thank you for your time and your consideration of this study.

Sincerely,

Jennifer Arms

Master's Student

Illinois State University

jaarms@ilstu.edu

309-202-4549 